Pediatr Clin North Am. 2013 December ; 60(6): 1311-1336. doi:10.1016/j.pcl.2013.08.011.

\title{
Acquired Aplastic Anemia in Children
}

\author{
Helge D. Hartung, MD ${ }^{\mathrm{a}, 1}$, Timothy S. Olson, MD, PhD ${ }^{\mathrm{b}, 1}$, and Monica Bessler, MD, PhD ${ }^{\mathrm{a}, \mathrm{C}}$ \\ aDivision of Hematology, Department of Pediatrics, Comprehensive Bone Marrow Failure Center, \\ The Children's Hospital of Philadelphia, 3615 Civic Center Boulevard, ARC 302, Philadelphia, PA \\ 19104, USA
}

bDivision of Oncology, Department of Pediatrics, Comprehensive Bone Marrow Failure Center, The Children's Hospital of Philadelphia, 3615 Civic Center Boulevard, ARC 302, Philadelphia, PA 19104, USA

'Division of Hemato-Oncology, Department of Medicine, Hospital of the University of Pennsylvania, Perelman School of Medicine, University of Pennsylvania, 3400 Spruce Street, 1218 Penn Tower, Philadelphia, PA 19104, USA

\section{SYNOPSIS}

This article provides a practice-based and concise review of the etiology, diagnosis, and management of acquired aplastic anemia in children. Bone marrow transplantation, immunosuppressive therapy, and supportive care are discussed in detail. The aim is to provide the clinician with a better understanding of the disease and to offer guidelines for the management of children with this uncommon yet serious disorder.

\section{Keywords}

Acquired aplastic anemia; Bone marrow failure; Immune-mediated aplastic anemia; Immune suppressive therapy for severe aplastic anemia in children; Bone marrow transplant for severe aplastic anemia in children

\section{Introduction}

Acquired aplastic anemia (AA) in childhood remains an uncommon, life-threatening disorder. Because of major advances in diagnosis and therapeutic approaches, AA in

\footnotetext{
(c) 2013 Elsevier Inc. All rights reserved.

Corresponding Author: Monica Bessler, MD, PhD, Pediatric \& Adult Comprehensive Bone, Marrow Failure Center at, The Children's Hospital of Philadelphia and, The Hospital of the University of Pennsylvania, Center Blvd, ARC 302, Philadelphia PA 19104, besslerm@email.chop.edu, Phone: 267-426-8782, Fax: 267-426- 9892.

${ }^{1}$ Equal contributing authors

Co-authors:

Helge D. Hartung, MD, The Children's Hospital of Philadelphia, 3615 Civic Center Blvd, ARC 302, Philadelphia PA 19104, hartungh1@email.chop.edu3615 Civic, Phone: 267-425-2126, Fax: 267-426- 9892

Timothy S. Olson, MD, PhD, The Children's Hospital of Philadelphia, 3615 Civic Center Blvd, ARC 302, Philadelphia PA 19104, olsont@email.chop.edu, Phone: 215- 620-8842, Fax: 267-426- 9892

Conflict of Interest:

Dr. Bessler: None

Dr. Hartung: None

Dr. Olson: None

Publisher's Disclaimer: This is a PDF file of an unedited manuscript that has been accepted for publication. As a service to our customers we are providing this early version of the manuscript. The manuscript will undergo copyediting, typesetting, and review of the resulting proof before it is published in its final citable form. Please note that during the production process errors may be discovered which could affect the content, and all legal disclaimers that apply to the journal pertain.
} 
children is today a disease that results in long-term survival in more than $90 \%$ of cases. Here, we will review current practices for diagnosis and therapy of patients with acquired AA, discuss alternative approaches, and assess the evidence base.

\section{Definitions}

AA is characterized by peripheral blood pancytopenia and a hypocellular bone marrow without dysplasia or fibrosis (Figure 1). The degree or severity of AA is defined by peripheral blood cell counts in the presence of a hypocellular bone marrow (see Box 1). ${ }^{1,2}$ AA in children is distinct from AA in adults; inherited AA is more frequently found in children, the HLA association differs, suggesting an age specific immune pathogenesis. Finally, there are age specific differences in treatment, response to treatment, treatment outcome and late manifestations.

\section{Box 1}

Definition of Severity of Aplastic Anemia

\begin{tabular}{|c|c|}
\hline $\begin{array}{l}\text { Moderate or Non-Severe } \\
\text { (NSAA) }\end{array}$ & $\begin{array}{l}\text { Decreased bone marrow cellularity and peripheral blood cytopenia, NOT fulfilling } \\
\text { criteria for SAA }\end{array}$ \\
\hline Severe $(\mathrm{SAA})^{l}$ & $\begin{array}{l}\text { Bone marrow cellularity }<25 \% \\
\text { AND at least two of the following: } \\
\text { a. Neutrophil count }<500 \times 10^{6} / 1 \\
\text { b. Platelet count }<20,000 \times 10^{6 / 1} \\
\text { c. Reticulocyte count }{ }^{3}<60,000 \times 10^{6 / 1}\end{array}$ \\
\hline Very severe (vSAA) ${ }^{2}$ & $\begin{array}{l}\text { Fulfilling criteria for SAA } \\
\text { PLUS } \\
\text { a. Neutrophil count }<200 \times 10^{6} / 1\end{array}$ \\
\hline $\begin{array}{l}\text { Camitta et al, } 1975^{5}, \\
{ }^{2} \text { Bacigalupo et al, } 1988^{6}\end{array}$ & \\
\hline
\end{tabular}

Acquired AA has to be distinguished from inherited bone marrow failure syndromes (IBMFS) and from hypoplastic myelodysplastic syndrome (MDS). IBMFS are more frequent in the pediatric population and comprise roughly 25-30\% of cases of bone marrow aplasia in children. ${ }^{3}$ Distinguishing between acquired AA and IBMFS can be difficult in patients with inherited conditions lacking classical congenital anomalies or in patients without a supporting family history, which can be due to a de novo mutation or a mutation with low disease penetrance. ${ }^{3}$. Figure 2 shows the interrelationship of acquired AA and IBMF from a genetic point of view.

Similarly, hypoplastic MDS can be difficult to differentiate from acquired AA (and IBMFS), especially in children. The new WHO classification for myeloid neoplasms distinguishes refractory cytopenia of childhood (RCC) from AA and considers it as a provisional entity of childhood MDS (Box 2). ${ }^{4}$ This new WHO classification is becoming increasingly established in Europe and Japan, but its application in North America is still limited. Of clinical importance is that RCC, although classified as a low risk childhood MDS entity, differs from the current broader concept of MDS in older adults, which is associated with a poor prognosis. Current diagnostics, care, and treatment for AA and RCC are largely the same, therefore in this review we do not distinguish between AA and RCC. Box 2 summarizes the histologic and morphologic criteria that differentiate AA from RCC. ${ }^{5}$. 
Prospective future and ongoing studies will determine the clinical significance of the RCC MDS entity.

\section{Box 2}

Differentiation of Aplastic Anemia (AA) and Refractory Cytopenia of Childhood (RCC) ${ }^{11}$

\begin{tabular}{|c|c|c|}
\hline & $\mathbf{A A}$ & RCC \\
\hline \multicolumn{3}{|l|}{ Erythropoiesis } \\
\hline Bone Marrow Histology: & $\begin{array}{l}\text { Decreased } \\
\text { Possible single large loci with } \\
<10 \text { cells }\end{array}$ & $\begin{array}{l}\text { Decreased } \\
\text { Left shifted, mitosis, clustered } \\
\text { +/- Dysplastic }\end{array}$ \\
\hline Peripheral blood & Decreased reticulocytes & $\begin{array}{l}\text { Increased } \mathrm{MCV} \\
\text { Increased fHb } \\
\text { Increased reticulocytes }\end{array}$ \\
\hline \multicolumn{3}{|l|}{ Granulopoiesis } \\
\hline Bone Marrow Histology: & Decreased & $\begin{array}{l}\text { Decreased } \\
\text { Left shifted } \\
+/- \text { Dysplastic }\end{array}$ \\
\hline \multicolumn{3}{|l|}{ Megakaryopoiesis } \\
\hline Bone Marrow Histology: & Decreased or absent & $\begin{array}{l}\text { Decreased } \\
\text { Dysplastic } \\
\text { Micomegakaryocytes }\end{array}$ \\
\hline $\begin{array}{l}\text { Dysplastic changes in the bone marrow } \\
\text { aspiratte }\end{array}$ & None & $\begin{array}{l}<10 \% \text { in two cell lineages } \\
>10 \% \text { in one lineage }\end{array}$ \\
\hline Reticulin in the bone marrow biopsy & No increase & No increase \\
\hline Cellularity the bone marrow biopsy & $<25 \%$ & Hypocellular \\
\hline Severity of cytopenia in peripheral blood & Frequently severe or very severe & Frequently severe or moderate \\
\hline Lymphocytes Bone Marrow Histology: & $\begin{array}{l}\text { May be increased focally or } \\
\text { dispersed }\end{array}$ & May be increased focally or dispersed \\
\hline $\begin{array}{l}\text { Blast in the bone marrow aspirate and } \\
\text { biopsy }\end{array}$ & Not increased & $<5 \%$ (<2\% peripheral blood $)$ \\
\hline Cytogenetics: & Absent, transient & More prevalent than in AA \\
\hline $\begin{array}{l}\text { Numerical or structural chromosomal } \\
\text { abnormality }\end{array}$ & & \\
\hline
\end{tabular}

Retics, reticulocyte count; MCV, Mean Corpuscular Volume; fHb, fetal Hemoglobin

Baumann I, Fuhrer M, Behrendt S, et al. Morphological differentiation of severe aplastic anaemia from hypocellular refractory cytopenia of childhood: reproducibility of histopathological diagnostic criteria. Histopathology. 2012;61:10-17.

\section{Epidemiology}

Acquired AA is a rare disorder with an incidence of about 2 per 1,000,000 children per year in North America and Europe and 2-3 fold higher in Asia. ${ }^{6}$ The peak incidence is in adolescence and in young adults as well as in the elderly, with a roughly equal male-tofemale ratio. ${ }^{6}$ A classification of AA based on etiology is summarized in Table 1. 


\section{Pathogenesis}

For many years, an immune-mediated pathogenesis has been postulated for AA because Immunosuppressive Therapy (IST) is often successful in the treatment of AA and bone marrow lymphocytes from AA patients can suppress normal bone marrow in vitro. ${ }^{7}$ Results from numerous laboratories have demonstrated increased cytokine expression, low CD4 T regulatory cells, oligoclonal CD8 cytotoxic T cells, and to a lesser extent, expansion of specific CD4 cell populations in the bone marrow of AA patients. ${ }^{8,9}$ Coupled with the recent finding of acquired copy number neutral loss of heterozygosity of the short arm of chromosome $6(6 \mathrm{pLOH})$, representing a likely genetic signature of immune escape,${ }^{10}$ these findings have strengthened the belief that bone marrow aplasia in acquired AA is immunemediated, replacing the conventional term "idiopathic AA" with "immune-mediated AA" (Figure 3).

\section{Clinical Presentation}

Most children with AA present with signs and symptoms resulting from advanced pancytopenia, while others are diagnosed by incidental laboratory findings.

Thrombocytopenia may manifest as easy bruising or petechiae. Epistaxis and menorrhagia in postmenarchal girls are other common complaints at presentation. Anemia may manifest as pallor, fatigue or exercise intolerance. Neutropenia may predispose to infections and thus fever or focal signs of infection can occur as initial complaints. Hepatosplenomegaly and lymphadenopathy are typically absent. A history of jaundice often occurring $2-3$ months prior to discovery of pancytopenia, is consistent with hepatitis-associated AA.

\section{Establishing the Diagnosis}

A comprehensive history should include exposure to medications, recreational drugs, and chemicals as well as preceding infectious symptoms. The family history needs to be detailed and assessed for diseases and signs suggestive of IBMFS (Table 2). A comprehensive laboratory panel is requested to establish the diagnosis of AA, to classify its severity, and to screen for potential causative factors (Table 3 ). A bone marrow aspirate and biopsy are needed to establish the diagnosis (Figure 1). A complete blood count, reticulocyte count and review of the peripheral blood smear confirm existing cytopenias and exclude signs of dysplasia. Review of the biopsy is required to grade the severity of disease (Box 1). AA can present with a hematopoietic cell clone that already lacks glycosyl phosphatidylinositol (GPI)-anchored proteins characteristic of Paroxysmal Nocturnal Hemoglobinuria (PNH) at the time of diagnosis. Flow cytometry for the absence of GPI-anchored proteins is used to detect an early PNH cell clone. ${ }^{11,12}$ However, due to leukopenia, testing for PNH at diagnosis has a poor sensitivity and needs to be repeated when neutrophil counts are recovering. Patients with acquired AA have deceased numbers of regulatory $\mathrm{T}$ cells (Treg, CD4+ CD25+ T cells). The number of Treg negatively correlates with the severity of disease and low Treg numbers were found to be associated with treatment failure. ${ }^{13}$ At the Comprehensive Bone Marrow Failure Center of the Children's Hospital of Philadelphia (CHOP), we routinely assess peripheral lymphocytes with chromosome breakage studies to rule out Fanconi Anemia (FA) and we perform telomere length analysis to rule out Dyskeratosis Congenita (DC). Because these tests may take several days to complete, and because results have a great impact on treatment decisions, we recommend performing these tests early in the evaluation. The initial clinical presentation of patients with either FA or DC may be indistinguishable from that seen in patients with acquired AA. Genetic testing to confirm the diagnosis of DC is ordered when a patient with an aplastic marrow has a telomere length in peripheral blood lymphocytes that is far below the first percentile of that 
in healthy controls (of note, different criteria are used for dyskeratosis in a non-aplastic patient). ${ }^{14}$

Bone marrow examination usually includes cytogenetic studies, including a karyotype and Fluoresence In Situ Hybridization (FISH) analysis for monosomy 7, trisomy 8, and others as indicated by the karyotype results. The utility of genome-wide Single-Nucleotide Polymorphism (SNP) arrays performed in addition to conventional cytogenetics currently remains investigational but may be helpful for the early detection of clonal hematopoiesis. 15,16

At our Center, we routinely obtain high resolution HLA typing, including a preliminary donor search at diagnosis in all patients who present with severe AA (SAA) and very severe AA (vSAA)(see Box 1), even in the absence of a potential sibling donor. Early HLA typing will expedite an unrelated donor search for patients refractory to IST, and will be beneficial for patients in whom the initial investigations reveal an underlying IBMFS diagnosis.

Early therapeutic interventions (IST $<4$ weeks and BMT $<12$ weeks from presentation) are associated with significantly improved outcomes in acquired AA. ${ }^{17}$ Thus, every effort should be made to complete diagnostic evaluations and to initiate therapy within 3-4 weeks of initial diagnosis.

\section{Supportive care}

Gains in survival for patients with acquired AA are due in part to the improvement in supportive therapy. ${ }^{18}$ However, infections and bleeding still remain a major cause of morbidity and mortality in this patient population. ${ }^{19,20}$ In an afebrile patient with a good performance status (ECOG/WHO/Zubrod 0-2) the evaluation of AA may be performed in the outpatient setting in a center and by a care team experienced in treating AA patients.

Although there is a lack of strong evidence for most strategies to prevent neutropenic infections, at our Center we prescribe basic neutropenic precautions for patients with neutrophil counts $<500 /$ ul (Table 4). We routinely use prophylactic antifungals for AA patients with prolonged ( $>7$ days) neutrophil counts $<500 / \mu \mathrm{l}^{21}$ or for AA patients on IST (Figure 4). In AA patients with lymphopenia $<500 /$ ul or those receiving IST, we provide Pneumocystis jiroveci pneumonia (PJP) prophylaxis. Three times weekly Trimethoprim/ sulfamethoxazole (co-trimoxazole, TMP/SMX) has been shown to be superior to oral dapsone, aerosolized pentamidine, or oral atovaquone in individuals with lymphopenia from HIV or chemotherapy, ${ }^{21}$ though due to its potential bone marrow toxicity TMP/SMX is frequently abandoned when recovery of AA is delayed. We therefore use aerosolized pentamidine as a first line PJP prophylaxis in children with AA, because it has good PJP protection in this patient population, and has a very good therapy patient compliance rates, due to its monthly dosing. 22

G-CSF alone is not a treatment of AA, and its routine use for patients with AA is controversial. At our Center, G-CSF is given to pediatric AA patients with neutrophil counts $<500 /$ ul in combination with IST. Prolonged use of high doses of G-CSF may increase the risk of clonal hematopoiesis and malignant transformation to MDS/AML. ${ }^{23}$

Neutropenic fever requires immediate attention and hospitalization with the initiation of antibiotic therapy according to pre-established hospital guidelines (i.e. Figure 4). For persistent fever or suspected fungal infection, galactomannan testing and CT scan of the chest are performed and empiric antifungal agents are started. In life-threatening situations, the use of granulocyte infusions may be considered to provide a bridge between treatment response and neutrophil recovery. 24 
Platelet transfusions should be considered to prevent bleeding in asymptomatic patients with platelet counts $<10,000 / \mu 1$. Higher thresholds for platelet transfusions are reserved for patients with either active bleeding or a history of significant bleeding complications. Higher thresholds $(<20,000 / \mu \mathrm{l})$ are also recommended in patients at risk for worsening thrombocytopenia (e.g. febrile patients or those receiving IST).

Transfusion policies in patients with AA are, in general, restrictive. Institutional policies vary; in our practice we transfuse red blood cell concentrates for hemoglobin under $8 \mathrm{~g} / \mathrm{dl}$ or if symptomatic. Leukodepleted and irradiated blood products should be given to reduce the risk of transfusion associated graft-versus-host disease (GVHD) and HLA sensitization. ${ }^{25}$ Iron chelation is initiated for patients who remain transfusion dependent over a prolonged time period. Iron chelation is performed with desferrioxamine or deferasirox. Deferiprone is not recommended for AA patients with iron overload because of the associated risk of agranulocytosis. ${ }^{26}$

Institutional policies and recommendations for vaccinations vary. At our Center, we do not recommend vaccination until one year after the cessation of IST, at which time ageappropriate vaccines may be resumed. We recommend the use of inactivated vaccines. Due to potential infectious complications from live attenuated vaccines, as well as due to the potential risk of AA relapse, live attenuated vaccines are not recommended in this population, though in each case the immunologic benefit of using attenuated live viruses has to be weighed against the potential risk of AA relapse.

Psychosocial support of patients and families and an age-appropriate explanation of disease, treatment, and prognosis are important at diagnosis and during the course of disease and improve therapy adherence and disease outcomes. Psychosocial support is particularly important at the time of pediatric to adult healthcare transition. Often there is a lack of ancillary support services to assist in care transition in the in the adult-care settings, which may result in a lack of continuity of care and poor therapy compliance.

\section{Definitive Treatment}

Once a diagnosis is firmly established, bone marrow transplantation (BMT) and immunosuppressive therapy (IST) are currently the primary treatment options for AA patients in children and adults. Numerous studies have established that BMT is highly successful when an HLA-matched sibling is available (matched related donor, MRD), with 5-year survival rates of $90 \%$ and higher, making BMT the recommended first-line therapy in this setting (Figure 5). In North America, we currently continue to reserve matched unrelated donor (URD) BMT for patients with SAA or vSAA who have failed IST. ${ }^{27}$ However, with improved outcomes for patients who undergo matched URD transplant and with better donor availability, URD transplant may become a first line therapy for patients with SAA or vSAA for whom a matched sibling is not available and for whom an excellent unrelated donor has been identified. Upfront URD transplant for children and young adults with SAA or vSAA is increasingly used in countries where horse ATG is no longer available because IST using an alternative agent, rabbit ATG, is associated with a lower response rate (see also below). ${ }^{28,29}$

\section{Bone Marrow Transplant}

The current standard approach to BMT for pediatric patients with acquired AA is summarized in Table 5. 


\section{Matched Related Donor Bone Marrow Transplantation for Aplastic Anemia}

Conditioning-Since the early 1990's, the standard conditioning regimen for matched related donor bone marrow transplantation (MRD-BMT) has been high dose cyclophosphamide $(\mathrm{Cy}, 200 \mathrm{mg} / \mathrm{kg}$ divided into 4 daily doses) plus anti-thymocyte globulin (Cy-ATG). ${ }^{30,31}$ Long-term analyses have shown that the CY-ATG regimen in MRD-BMT for acquired AA results in decreased rates of GVHD and improved long-term overall survival compared to regimens that include total body irradiation (TBI). ${ }^{32,33}$ Currently, engraftment rates using CY-ATG are as high as $96 \%,{ }^{32}$ with overall survival (OS) in children estimated at $91 \%$ compared to $74 \%$ in adults. ${ }^{17}$ Interestingly, a recent randomized trial comparing outcomes for acquired AA patients receiving MRD-BMT with either CY alone or CY- ATG demonstrated no difference in graft failure, GvHD, or OS between the two regimens, ${ }^{34}$ calling into question whether ATG is still needed in the MRD-BMT regimen for acquired AA, given the decreased risk of allo-immunization in the current era of first-line MRD-BMT therapy and leukoreduced blood products.

In older adults, fludarabine-containing regimens that enable dose reduction of cyclophosphamide (FLU-CY) are replacing CY $200 \mathrm{mg} / \mathrm{kg}$ regimens in order to reduce organ cytotoxicity and intensify immune suppression, resulting in improved OS. ${ }^{35}$ Small pediatric case series have shown excellent survival and engraftment with regimens containing fludarabine $\left(180 \mathrm{mg} / \mathrm{m}^{2}\right)$ and dose-reduced CY $(120 \mathrm{mg} / \mathrm{kg}){ }^{36,37}$ While such a regimen may decrease rates of alkylating agent-induced gonadal dysfunction ${ }^{38-40}$, prospective randomized trials are needed to compare efficacy versus standard Cy-ATG regimens.

Graft source-Peripheral blood stem cells (PBSC) are increasingly used in matched sibling allogeneic transplantation for malignant conditions. However, retrospective analysis in patients undergoing MRD transplantation for acquired AA demonstrated a significant decrease in 5 year OS in pediatric acquired AA patients receiving PBSC (73\%) versus BM (85\%) grafts, likely due to a markedly increased incidence in chronic GVHD occurring in recipients of PBSC's versus BM (27\% versus $12 \%) .{ }^{41}$ Therefore, unlike in transplantation for pediatric malignancies, where PBSC may elicit beneficial graft-versus-leukemia effects, $\mathrm{BM}$ is clearly the preferred stem cell source for acquired AA patients.

Graft Failure, GVHD, and donor chimerism—Rates of primary graft failure following MRD-BMT for acquired AA patients have declined from greater than $30 \%$ in early studies to current rates of $<10 \%, 30,32$ in large part due to decreased time to initial BMT, decreased transfusion exposure, and increased use of leukoreduced blood products. ${ }^{42}$ Both acute and chronic GVHD remain a significant source of short and long term morbidity for patients receiving MRD-BMT for acquired AA. ${ }^{40}$ Prior studies demonstrated superiority of short course methotrexate + cyclosporine (MTX+CSA) versus cyclosporine (CSA) alone in prevention of GVHD and improvement in OS $;^{43}$ thus MTX-CSA remains the standard of care GVHD prophylaxis regimen. However, recent series have not identified differences in survival in comparisons of CSA versus MTX+CSA prophylaxis regimens, ${ }^{17}$ while another prospective study has demonstrated equivalence of mycophenolate (MMF) plus CSA with MTX-CSA regimens in terms of GVHD incidence, with improvement in time to neutrophil engraftment in the MMF arm. ${ }^{44}$ Tacrolimus appears to have equivalent efficacy compared to CSA in preventing GVHD. ${ }^{45} \mathrm{CSA} /$ tacrolimus should be continued for at least 6 months post-transplantation in AA patients, followed by a slow taper, as this prolonged course serves not only to prevent GVHD, but also to prevent secondary graft failure and relapse of BM aplasia. ${ }^{46}$ 
Mixed donor/recipient chimerism occurs in $44-55 \%$ of acquired AA patients following MRD-BMT ${ }^{40,46}$. A study of serial chimerism analysis in acquired AA patients indicates that while many develop transient or stable mixed chimerism, patients who exhibit progressive decline in donor chimerism, particularly during withdrawal of immune suppression, are at highest risk for late graft rejection and poor OS. ${ }^{46}$ In contrast to the standard approach following BMT for leukemia, where immune suppression is withdrawn in response to falling donor chimerism, current recommendations include serial chimerism analysis and reinstitution of immune suppression for acquired AA patients with falling donor chimerism post-BMT.

\section{Alternative Donor Bone Marrow Transplantation for Aplastic Anemia}

Donor Selection-Outcomes following unrelated donor transplantation (URD-BMT) for acquired AA have improved dramatically since the early 1990's, when OS was typically $<40 \%{ }^{43}$ This improvement is in large part due to improved sensitivity in methods of HLA typing and donor matching. In recent pediatric series using fully or closely matched donors, long term OS following URD-BMT for acquired AA ranges from 78-94\% 47,48 of patients, approaching the survival reported for MRD-BMT. Unfortunately, patients lacking a closely HLA-matched unrelated or related donor who undergo mismatched URD-BMT continue to exhibit poor outcomes, with several studies suggesting survival less than $40 \% .{ }^{42}$ Thus at present, transplant approaches for acquired AA patients without a closely matched URD should only be undertaken in the setting of ongoing clinical trials.

Unrelated cord blood transplantation (CBT) has had limited success in acquired AA patients. A large retrospective series including both pediatric and adult patients demonstrated a disappointing 3 year OS of $38 \%,{ }^{49}$ with graft failure the major cause of mortality. However, smaller case series restricted to pediatric patients have shown better rates of engraftment and OS, confirming the need for further pediatric studies. ${ }^{42}$ Interestingly, the successful use of autologous cord blood units in restoring hematopoiesis in pediatric acquired AA patients has now been reported, ${ }^{50}$ sparking new debate regarding utility of private cord banking programs. Haploidentical stem cell transplantation (HaploSCT) from related donors using unmanipulated grafts has previously been associated with very poor outcomes; however, recent successes have been achieved with HaploSCT in pediatric acquired AA patients using partial $\mathrm{T}$ cell depletion strategies to promote engraftment and OS. ${ }^{51} \mathrm{Co}$-infusion of donor mesenchymal stem cells may promote immunologic tolerance, further enabling enhanced donor engraftment following haploSCT. ${ }^{52}$

Conditioning Regimens-Optimal conditioning regimens for URD-BMT in acquired AA remain controversial. ${ }^{53}$ High dose (HD) total body irradiation (TBI) containing regimens can overcome the increased risk of graft failure in URD-BMT for pediatric acquired $\mathrm{AA}$, and combined with partial $\mathrm{T}$ cell depletion, improve $\mathrm{OS}$ versus regimens containing CY alone. ${ }^{54}$ However, HD TBI regimens cause high rates of both early toxicity and late effects. ${ }^{39}$ Subsequent studies have suggested that a lower dose of TBI (200 cGy) combined with full dose CY, enables high OS with lower regimen-related toxicity. ${ }^{53}$ Importantly, European data suggests that addition of fludarabine to regimens containing $\mathrm{Cy}$ and ATG enables the elimination of TBI altogether for acquired AA patients < 14 years of age receiving URD-BMT, with an OS of $84 \%$ and a graft failure rate of $5 \% .{ }^{55}$ In the United States, ongoing studies including pediatric patients are using fludarabine with $200 \mathrm{cGy}$ of TBI, while investigating dose reduction of $\mathrm{Cy} .{ }^{35}$ In our center, we are conducting a prospective study of alemtuzumab, fludarabine, and melphalan reduced intensity conditioning for matched URD transplantation in patients with non-malignant disorders including acquired AA. To date, 3 of 3 acquired AA patients have been treated successfully 
with this regimen with a follow-up of greater than 2 years post-transplantation (Nancy Bunin, personal communication).

\section{Follow-up and Late Effects after Stem Cell Transplantation for Acquired AA}

For acquired AA patients receiving BMT, we require follow-up in a specialized blood and marrow transplant clinic for at least one year post-transplant. Because of limited adaptive immune reconstitution during this time, fevers are treated aggressively with blood cultures and parenteral antibiotics until systemic infection is ruled-out. Pneumocystis prophylaxis is continued through the first year post- BMT, as is anti-viral prophylaxis based on donor and recipient serologies. Following the first year post-transplant and in the absence of complications such as organ toxicity, GVHD, or graft failure, care is gradually transitioned back to the primary pediatrician. Full re-immunization is recommended beginning at 1 year post-transplant, or when adequate immune reconstitution is documented.

While follow-up continues in specialized transplant clinics beyond the first year post-BMT, general pediatricians often play a critical role in early recognition of the late complications of BMT (Table 6). Routine screening should include assessments of growth, endocrine function, pulmonary function, bone health, and cancer screening to ensure prompt detection and therapy of potential late effects. Long-term follow-up for late effects of therapy in pediatric aplastic anemia patients is now available out to nearly 4 decades posttreatment ${ }^{32,33,38,39}$. In general, pediatric acquired AA patients who received MRD-BMT with CY-based regimens that do not contain TBI have excellent long-term outcomes, with normal growth rates and normal thyroid function. While transient ovarian dysfunction is common, most pre-pubertal girls receiving MRD-BMT without TBI progress normally through puberty with preserved gonadal function and fertility, whereas males receiving high dose CY regimens without TBI may develop prolonged azoospermia or exhibit abnormalities in pubertal development. ${ }^{39}$ Recipients of TBI-containing regimens have much higher incidences of cataracts, thyroid abnormalities, gonadal dysfunction, and infertility than patients not receiving TBI, ${ }^{50}$ though incidences of late effects caused specifically by low dose TBI (200 cGy) regimens now used in URD-BMT are less well-defined.

In contrast to acquired AA treated with IST, patients treated with BMT rarely develop leukemia or MDS. However, incidence of solid malignancy exceeds $10 \%$ when patient follow-up is extended beyond 15 years ${ }^{32,33,39}$, with major risk factors including TBI-based conditioning and chronic GvHD. A recent large series demonstrated a chronic GVHD 5 year cumulative incidence of $22 \%$ and $37 \%$ for MRD-BMT and URD-BMT, respectively. ${ }^{38}$ In addition to increased risk of malignancy, pediatric acquired AA patients who develop chronic GVHD post-BMT have a much higher incidence of gonadal dysfunction, pulmonary function deficits, avascular necrosis and abnormal bone density than patients without chronic GVHD. ${ }^{38}$

\section{Immunosuppressive Therapy}

Immunosuppressive therapy (IST) is currently the first-line therapy for patients with SAA or vSAA who lack a MRD (Figure 5). The majority of centers treating patients with AA, use anti-thymocyte globulin (ATG) and CSA as their first-line IST. In the United States horse ATG (hATG, ATGAM, Upjohn, Kalamazoo, MI) is most commonly used. Table 7 summarizes the IST treatment algorithm using hATG ATGAM. A short course of corticosteroids is used to reduce the risk of serum sickness. There is no other role for corticosteroids in AA, thus dosing should be adjusted accordingly. The addition of CSA to hATG has significantly increased the response to treatment $(65 \%$ hATG+CSA versus $31 \%$ ATG alone at 6 months $)^{56}$ and in multiple studies has shown an excellent overall 10 year survival of $82-93 \% .{ }^{57} \mathrm{CSA}$ is usually started with ATG, but may also be given after the 
completion of ATG infusion, in patients with liver or kidney dysfunction or in those with pre-existing hypertension which often results in a better tolerance of the ATG+CSA regiment. In children an increased rate of relapse was associated with a rapid CSA discontinuation $(60 \% \text { versus } 7.6 \%)^{58}$ and $15-25 \%$ of children remained CSA-dependent. ${ }^{58}$ Thus, in children it is recommended that CSA should generally be continued for at least 12 months after stable remission has been obtained, and should be followed by a slow taper over a minimum of 12 months. ${ }^{57,59}$

In Europe horse ATG (Lymphoglobuline; Genzyme Corporation, Cambridge, MA) has most commonly been used until recently. ${ }^{60}$ However, horse ATG is no longer available in Europe and Japan, so currently rabbit ATG (rATG, Thymoglobuline, Genzyme) is used $(3.75 \mathrm{mg} / \mathrm{kg}$ for 5 days). Importantly, several retrospective studies demonstrated that $\mathrm{rATG}$ is inferior compared to hATG, with a lower response rate at 6 months and an increased rate of infections leading to a decreased overall survival at 2 years, ${ }^{19,20}$ Although these findings have not been observed in all primarily retrospectives studies, none of the studies showed that rATG is superior to hATG. A recent retrospective study focusing on children confirmed a lower response rate at 6 months (36\% for rATG and 65\% for hATG) although, because of second line URD-BMT, 3-year overall survival was similar at $92 \%$ in both groups. ${ }^{29}$ Thus, current IST recommendations for the treatment of AA children should include hATG and URD BMT should be offered to all non-responders early in the course of disease (3-6 months). ${ }^{27}$

\section{G-CSF}

While G-CSF alone is not recommended for the treatment of AA, the addition of G-CSF to ATG and CSA in SAA and vSAA patients increases neutrophil counts and reduces infections and days of hospitalization in the first 3 months of treatment, but has no impact on survival, response to treatment or relapse. ${ }^{61}$

\section{Alternative first line therapies}

Over the years a number of newer immune suppressive agent have been investigated in order to improve the outcome of front-line IST in AA; these included mycophenolate mofetil, sirolimus, and alemtuzumab, and none showed improved responses, or decreased relapse or clonal evolution. Tacrolimus as an alternative to CSA showed a comparable response rate in children with a more favorable toxicity profile: however this study was not powered to definitively assess the statistical analysis of relapse. ${ }^{62}$ The addition of danazol to IST in children with AA was associated with a significant increase in relapse. ${ }^{63} \mathrm{High}$-dose cyclophosphamide (CY) without stem cell support is used by the Johns Hopkins Group ${ }^{64}$ as a first line therapy for pediatric and adult AA with comparable response rates to IST with hATG and CSA. However because of prolonged neutropenia associated with this protocol, high dose CY is usually only considered as a second or third line therapy by most centers.

Recently eltrombopag, a small, non-peptide thrombopoietin receptor (c-MPL) agonist, has been shown to improve hematopoiesis in 11 out of 25 adult AA patients who were refractory to IST; including 6 patients who showed improvement in all 3 blood cell lineages. ${ }^{65}$ While these results suggest that eltrombopag, and possible other thrombopoietin receptor (c-MPL) agonists, may represent a new approach for the treatment of acquired AA, a major concern is possible increased risk of clonal evolution and leukemia. ${ }^{65}$ Thus, pending additional studies, eltrombopag or other thrombopoietin receptor (c-MPL) agonists should be restricted to clinical trial settings. 


\section{Moderate or Non-Severe AA (NSAA)}

The approach to patients with moderate aplastic anemia is less defined. Studies on the natural history of NSAA are inconsistent, most likely because of the heterogeneity of this patient population, differences in the study populations (pediatric versus adult NSAA), and the difficulty in excluding IBMFS and low-grade MDS. Often patients with NSAA require only supportive therapy and no specific treatment for their cytopenia. NSAA may resolve spontaneously or progress to SAA. In children transformation to MDS or leukemia in patients who were cytogenetically normal at diagnosis is rare.${ }^{66-68}$ For NSAA patients who show signs of progression, or who are transfusion dependent, IST is suggested as the first choice of treatment. In adult patients with NSAA hATG+ CSA was found to be superior compared to CSA alone (30\% at 6 months for CSA alone and 65\% for hAG+CSA); both groups had excellent long-term overall survival (>90\%), though relapse was more frequent is CSA alone. ${ }^{69}$

\section{Response, Relapse and Late Effects after IST for Acquired AA}

\section{Response}

A complete response $(\mathrm{CR})$ is defined as a normalization of peripheral blood values in at least 2 separate blood cell counts at least 4 weeks apart (Box 3). Response is usually assessed 3, 6 and 12 months after ATG initiation. Response to treatment usually occurs within 3 to 6 months of treatment initiation but in some patients response may be delayed. The 6 months response rate for hATG+CSA varies among studies from $60 \%$ to $77 \%$, with these recent studies estimating a current 10-year overall survival of about $80 \%$ (in children about $90 \%-$ 93\%) and a relapse rate of $10 \%$ to $33 \% .{ }^{27}$ In adult AA patients there is an increased frequency for HLA-DR2, particularly HLA-DRB $1 * 15$, and this was associated with an improved response to IST with cyclosporine, ${ }^{70,71}$. Neither association was confirmed in children. ${ }^{72,73}$ In contrast in children an increased frequency of HLA-B14 was associated with SAA. ${ }^{72}$

\begin{tabular}{|l|ll|}
\hline Complete Response (CR) & - & Red blood cell and platelet transfusion independence \\
& - & Absolute neutrophil count $>1,500 \times 10^{6} / 1$ \\
& Platelet count $>150,000 \times 10^{6} / 1$ \\
\hline Partial Response (PR) & - & $\begin{array}{l}\text { Improvement of cytopenia with absolute neutrophil count } 2500 \times 10^{6} / 1 \text { and } \\
\text { platelets } 20,000 \times 10^{6} / 1 \\
+/- \text { Transfusion dependent }\end{array}$ \\
& - & $\begin{array}{l}\text { Continues to meet SAA criteria } \\
\text { No Response }\end{array}$ \\
& Ongoing transfusion dependence \\
\hline Relapse & - & Meets criteria of SAA or vSAA after initial response \\
\hline
\end{tabular}

\section{Relapse}

Relapse is highest during the first 3 years of IST therapy. ${ }^{63,74}$

\section{Second line therapy}

For children without an MRD, who relapse or are refractory to first line IST, URD transplant should be considered if a suitable matched donor is available (Figure 5). ${ }^{28,75}$ In children 
with IST-refractory SAA or vSAA an early URD BMT is suggested (3-6 months after initial IST). If a matched URD is not available, relapse or initial IST -refractory patients are usually treated with a second course of hATG+CSA or with $\mathrm{rATG}+\mathrm{CSA}$. In contrast to its use in first-line therapy (response rate of 30-40\%, see above), rATG used at relapse has a response rate of $65 \%$, though only $30 \%$ for patients who failed first-line hATG+CSA ${ }^{76}$

\section{Late complications}

Clonal evolution of hematopoiesis and PNH is thought to occur in about 10-20\% of AA patients, with the clonal abnormality frequently detected at diagnosis. Clonal hematopoiesis and PNH may also develop several years after IST treatment when it is usually associated either with hemolysis (PNH) or with a worsening of peripheral blood counts (clonal cytogenetic abnormality). ${ }^{16}$

The long-term follow-up of patients after IST is summarized in Table 8. We generally perform a repeat bone marrow aspirate and biopsy at 3 and 12 months after IST initiation to assess for treatment response and to monitor for clonal evolution. Monitoring for the development of PNH after IST is performed yearly using flow cytometry (see above). In adult AA patients chromosomal abnormalities are seen in about 10-15\% of patients, with many abnormalities being transient, and not necessarily associated with a poor prognosis. ${ }^{77,78}$ Persistent abnormalities of chromosome 7, however, are frequently associated with progression to MDS. ${ }^{56,79}$ In children with AA, persistent chromosomal abnormalities of chromosome 7 and 8 , or complex cytogenetic abnormalities, are generally considered as MDS with and are associated with an increased risk of transformation, and treated accordingly, ${ }^{80}$ whereas the clinical significance of other chromosomal abnormalities i.e. $6 \mathrm{p} \mathrm{CN} \mathrm{LOH} \mathrm{remains} \mathrm{to} \mathrm{be} \mathrm{determined.}$

Patients after IST also have an increased risk for the development of autoimmune disease $(10 \%)^{81}$ and solid tumors $(11 \%)^{82}$. Thus children with a history of AA should be followed indefinitely, and age-appropriately, in a specialized bone marrow failure center, irrespective of whether they have undergone BMT or IST.

\section{In summary}

Acquired AA is a rare, life-threatening disorder, which is thought to be due to immunemediated destruction of hematopoietic cells in the bone marrow. Great advances have been made in the last decade in the understanding of its pathogenesis as well as in the care and treatment of children with AA, which is now associated with excellent overall survival surpassing $90 \%$. Allogeneic BMT offers the opportunity for cure in children if a suitable histocompatible donor is available. Comparable long-term survival in SAA is achieved with IST. However, one quarter of AA children will not respond to primary IST and will require second-line therapy, $10-30 \%$ of responders will relapse, and there is an increased risk of clonal hematopoiesis, leukemia, autoimmunity, and cancer that requires a long-term followup by a specialized care center knowledgeable in late manifestations of disease. With an increased understating of the pathogenesis of AA and its specific late manifestations targeted preventative strategies and more personalized treatment options are likely to further improve outcomes and decrease late complications in children (and adults) with acquired AA.

\section{Acknowledgments}

We thank all patients with AA for participating in our BMF studies at CHOP/UPENN, Beverly J Paul RN, for her contributions in the care of BMF patients, Michele E. Paessler D.O., Pathology, CHOP, for providing the images used in Figure 1, and Talene Metjian PharmD, Brian T. Fisher, DO MSCE, Infectious Diseases, and Shefali Parikh, MD, Hematology, The Children's Hospital of Philadelphia, for sharing the algorithm for anti-infective prophylaxis 
in patients with SAA shown in Figure 5, Neil Patel PharmD, BCOP, Clinical Pharmacists, CHOP, for input and discussions on the IST therapy protocol and Daria Babushok MD PhD, and Philip Mason PhD for reading the manuscript. This work is supported by the NHLBI K12 HL087064, The Canuso Foundation Innovation Grant, and CHOP CTRC Junior Investigator Pilot Grant Program (Funded by NCATS NIH UL1TR000003) to TSO, the NCI NIH R01 CA105312 and Buck Family Endowed Chair in Hematology to MB.

\section{References}

1. Camitta BM, Rappeport JM, Parkman R, et al. Selection of patients for bone marrow transplantation in severe aplastic anemia. Blood. 1975; 45:355-363. [PubMed: 1090310]

2. Bacigalupo A, Hows J, Gluckman E, et al. Bone marrow transplantation (BMT) versus immunosuppression for the treatment of severe aplastic anaemia (SAA): a report of the EBMT SAA working party. Br J Haematol. 1988; 70:177-182. [PubMed: 3056497]

3. Bessler, M.; Mason, P.; Link, D., et al. Inherited bone marrrow failure syndromes. In: DGN; SHO; DG, et al., editors. Nathans and Oski's Hematology of infancy and childhood. 8. Philadelphia: W. B. Saunders Co; 2014.

4. Baumann, I.; Niemeyer, C.; Bennett, J., et al. Childhood myelodysplastic syndrome. In: Swerdlow, S.; EC; NLH, et al., editors. WHO classification of tumors of haematopoietic and lymphoid tissue. Vol. 2. Lyon: International Agency for Research on Cancer; 2008. p. 104-107.

5. Baumann I, Fuhrer M, Behrendt S, et al. Morphological differentiation of severe aplastic anaemia from hypocellular refractory cytopenia of childhood: reproducibility of histopathological diagnostic criteria. Histopathology. 2012; 61:10-17. [PubMed: 22458667]

6. Montane E, Ibanez L, Vidal X, et al. Epidemiology of aplastic anemia: a prospective multicenter study. Haematologica. 2008; 93:518-523. [PubMed: 18322256]

7. Kagan WA, Ascensao JA, Pahwa RN, et al. Aplastic anemia: presence in human bone marrow of cells that suppress myelopoiesis. Proc Natl Acad Sci U S A. 1976; 73:2890-2894. [PubMed: 1085449]

8. Risitano AM, Maciejewski JP, Green S, et al. In-vivo dominant immune responses in aplastic anaemia: molecular tracking of putatively pathogenetic T-cell clones by TCR beta-CDR3 sequencing. Lancet. 2004; 364:355-364. [PubMed: 15276395]

9. Kordasti S, Marsh J, Al-Khan S, et al. Functional characterization of CD4+ T cells in aplastic anemia. Blood. 2012; 119:2033-2043. [PubMed: 22138514]

10. Katagiri T, Sato-Otsubo A, Kashiwase K, et al. Frequent loss of HLA alleles associated with copy number-neutral 6pLOH in acquired aplastic anemia. Blood. 2011; 118:6601-6609. [PubMed: 21963603]

11. Sutherland DR, Kuek N, Davidson J, et al. Diagnosing PNH with FLAER and multiparameter flow cytometry. Cytometry B Clin Cytom. 2007; 72:167-177. [PubMed: 17285629]

12. Bessler M, Fehr J. Fc III receptors (FcRIII) on granulocytes: a specific and sensitive diagnostic test for paroxysmal nocturnal hemoglobinuria (PNH). Eur J Haematol. 1991; 47:179-184. [PubMed: 1833236]

13. Sutton KS, Shereck EB, Nemecek ER, et al. Immune markers of disease severity and treatment response in pediatric acquired aplastic anemia. Pediatr Blood Cancer. 2013; 60:455-460. [PubMed: 22811079]

14. Du HY, Pumbo E, Ivanovich J, et al. TERC and TERT gene mutations in patients with bone marrow failure and the significance of telomere length measurements. Blood. 2009; 113:309-316. [PubMed: 18931339]

15. Kojima S, Nakao S, Young N, et al. The Third Consensus Conference on the treatment of aplastic anemia. Int J Hematol. 2011; 93:832-837. [PubMed: 21617886]

16. Babushok, DV.; Xie, HM.; Roth, JJ., et al. Single Nucleotide Polymorphism array analysis of bone marrow failure patients reveals characteristic patterns of genetic changes. 2013. submitted

17. Locasciulli A, Oneto R, Bacigalupo A, et al. Outcome of patients with acquired aplastic anemia given first line bone marrow transplantation or immunosuppressive treatment in the last decade: a report from the European Group for Blood and Marrow Transplantation (EBMT). Haematologica. 2007; 92:11-18. [PubMed: 17229630] 
18. Valdez JM, Scheinberg P, Nunez O, et al. Decreased infection-related mortality and improved survival in severe aplastic anemia in the past two decades. Clin Infect Dis. 2011; 52:726-735. [PubMed: 21367725]

19. Marsh JC, Bacigalupo A, Schrezenmeier H, et al. Prospective study of rabbit antithymocyte globulin and cyclosporine for aplastic anemia from the EBMT Severe Aplastic Anaemia Working Party. Blood. 2012; 119:5391-5396. [PubMed: 22544699]

20. Scheinberg P, Nunez O, Weinstein B, et al. Horse versus rabbit antithymocyte globulin in acquired aplastic anemia. N Engl J Med. 2011; 365:430-438. [PubMed: 21812672]

21. Neumann S, Krause SW, Maschmeyer G, et al. Primary prophylaxis of bacterial infections and Pneumocystis jirovecii pneumonia in patients with hematological malignancies and solid tumors: guidelines of the Infectious Diseases Working Party (AGIHO) of the German Society of Hematology and Oncology (DGHO). Ann Hematol. 2013; 92:433-442. [PubMed: 23412562]

22. Quarello P, Saracco P, Giacchino M, et al. Epidemiology of infections in children with acquired aplastic anaemia: a retrospective multicenter study in Italy. Eur J Haematol. 2012; 88:526-534. [PubMed: 22381133]

23. Ohara A, Kojima S, Hamajima N, et al. Myelodysplastic syndrome and acute myelogenous leukemia as a late clonal complication in children with acquired aplastic anemia. Blood. 1997; 90:1009- 1013. [PubMed: 9242530]

24. Quillen K, Wong E, Scheinberg P, et al. Granulocyte transfusions in severe aplastic anemia: an eleven-year experience. Haematologica. 2009; 94:1661-1668. [PubMed: 19996117]

25. Marsh J, Socie G, Tichelli A, et al. Should irradiated blood products be given routinely to all patients with aplastic anaemia undergoing immunosuppressive therapy with antithymocyte globulin (ATG)? A survey from the European Group for Blood and Marrow Transplantation Severe Aplastic Anaemia Working Party. Br J Haematol. 2010; 150:377-379. [PubMed: 20528874]

26. Jamuar SS, Lai AH. Safety and efficacy of iron chelation therapy with deferiprone in patients with transfusion-dependent thalassemia. Ther Adv Hematol. 2012; 3:299-307. [PubMed: 23616917]

27. Samarasinghe S, Steward C, Hiwarkar P, et al. Excellent outcome of matched unrelated donor transplantation in paediatric aplastic anaemia following failure with immunosuppressive therapy: a United Kingdom multicentre retrospective experience. Br J Haematol. 2012; 157:339-346. [PubMed: 22372373]

28. Bacigalupo A, Marsh JC. Unrelated donor search and unrelated donor transplantation in the adult aplastic anaemia patient aged 18-40 years without an HLA-identical sibling and failing immunosuppression. Bone Marrow Transplant. 2013; 48:198-200. [PubMed: 23178545]

29. Yoshimi A, Niemeyer CM, Fuhrer MM, et al. Comparison of the efficacy of rabbit and horse antithymocyte globulin for the treatment of severe aplastic anemia in children. Blood. 2013; 121:860- 861. [PubMed: 23372153]

30. Armand P, Antin JH. Allogeneic stem cell transplantation for aplastic anemia. Biol Blood Marrow Transplant. 2007; 13:505-516. [PubMed: 17448909]

31. Bunin N, Leahey A, Kamani N, et al. Bone marrow transplantation in pediatric patients with severe aplastic anemia: cyclophosphamide and anti-thymocyte globulin conditioning followed by recombinant human granulocyte-macrophage colony stimulating factor. J Pediatr Hematol Oncol. 1996; 18:68-71. [PubMed: 8556374]

32. Kahl C, Leisenring W, Deeg HJ, et al. Cyclophosphamide and antithymocyte globulin as a conditioning regimen for allogeneic marrow transplantation in patients with aplastic anaemia: a longterm follow-up. Br J Haematol. 2005; 130:747-751. [PubMed: 16115132]

33. Ades L, Mary JY, Robin M, et al. Long-term outcome after bone marrow transplantation for severe aplastic anemia. Blood. 2004; 103:2490-2497. [PubMed: 14656884]

34. Champlin RE, Perez WS, Passweg JR, et al. Bone marrow transplantation for severe aplastic anemia: a randomized controlled study of conditioning regimens. Blood. 2007; 109:4582-4585. [PubMed: 17272503]

35. Pulsipher MA, Young NS, Tolar J, et al. Optimization of therapy for severe aplastic anemia based on clinical, biologic, and treatment response parameters: conclusions of an international working 
group on severe aplastic anemia convened by the Blood and Marrow Transplant Clinical Trials Network, March 2010. Biol Blood Marrow Transplant. 2011; 17:291-299. [PubMed: 21034841]

36. George B, Mathews V, Viswabandya A, et al. Fludarabine based reduced intensity conditioning regimens in children undergoing allogeneic stem cell transplantation for severe aplastic anemia. Pediatr Transplant. 2008; 12:14-19. [PubMed: 18086256]

37. Resnick IB, Aker M, Shapira MY, et al. Allogeneic stem cell transplantation for severe acquired aplastic anaemia using a fludarabine-based preparative regimen. Br J Haematol. 2006; 133:649654. [PubMed: 16704442]

38. Buchbinder D, Nugent DJ, Brazauskas R, et al. Late effects in hematopoietic cell transplant recipients with acquired severe aplastic anemia: a report from the late effects working committee of the center for international blood and marrow transplant research. Biol Blood Marrow Transplant. 2012; 18:1776-1784. [PubMed: 22863842]

39. Sanders JE, Woolfrey AE, Carpenter PA, et al. Late effects among pediatric patients followed for nearly 4 decades after transplantation for severe aplastic anemia. Blood. 2011; 118:1421-1428. [PubMed: 21653322]

40. Konopacki J, Porcher R, Robin M, et al. Long-term follow up after allogeneic stem cell transplantation in patients with severe aplastic anemia after cyclophosphamide plus antithymocyte globulin conditioning. Haematologica. 2012; 97:710-716. [PubMed: 22180425]

41. Schrezenmeier H, Passweg JR, Marsh JC, et al. Worse outcome and more chronic GVHD with peripheral blood progenitor cells than bone marrow in HLA-matched sibling donor transplants for young patients with severe acquired aplastic anemia. Blood. 2007; 110:1397-1400. [PubMed: 17475907]

42. Myers KC, Davies SM. Hematopoietic stem cell transplantation for bone marrow failure syndromes in children. Biol Blood Marrow Transplant. 2009; 15:279-292. [PubMed: 19203719]

43. Young NS, Bacigalupo A, Marsh JC. Aplastic anemia: pathophysiology and treatment. Biol Blood Marrow Transplant. 2010; 16:S119-125. [PubMed: 19782144]

44. Ostronoff F, Ostronoff M, Souto-Maior AP, et al. Prospective trial of mycophenolate mofetilcyclosporine A prophylaxis for acute GVHD after G-CSF stimulated allogeneic bone marrow transplantation with HLA-identical sibling donors in patients with severe aplastic anemia and hematological malignancies. Clin Transplant. 2009; 23:33-38. [PubMed: 18727660]

45. Yagasaki H, Kojima S, Yabe H, et al. Tacrolimus/Methotrexate versus cyclosporine/methotrexate as graft-versus-host disease prophylaxis in patients with severe aplastic anemia who received bone marrow transplantation from unrelated donors: results of matched pair analysis. Biol Blood Marrow Transplant. 2009; 15:1603-1608. [PubMed: 19896085]

46. Lawler M, McCann SR, Marsh JC, et al. Serial chimerism analyses indicate that mixed haemopoietic chimerism influences the probability of graft rejection and disease recurrence following allogeneic stem cell transplantation (SCT) for severe aplastic anaemia (SAA): indication for routine assessment of chimerism post SCT for SAA. Br J Haematol. 2009; 144:933-945. [PubMed: 19183198]

47. Maury S, Bacigalupo A, Anderlini P, et al. Improved outcome of patients older than 30 years receiving HLA-identical sibling hematopoietic stem cell transplantation for severe acquired aplastic anemia using fludarabine-based conditioning: a comparison with conventional conditioning regimen. Haematologica. 2009; 94:1312-1315. [PubMed: 19734425]

48. Yagasaki H, Takahashi Y, Hama A, et al. Comparison of matched-sibling donor BMT and unrelated donor BMT in children and adolescent with acquired severe aplastic anemia. Bone Marrow Transplant. 2010; 45:1508-1513. [PubMed: 20118992]

49. Peffault de Latour R, Purtill D, Ruggeri A, et al. Influence of nucleated cell dose on overall survival of unrelated cord blood transplantation for patients with severe acquired aplastic anemia: a study by eurocord and the aplastic anemia working party of the European group for blood and marrow transplantation. Biol Blood Marrow Transplant. 2011; 17:78-85. [PubMed: 20561593]

50. Buchbinder D, Hsieh L, Puthenveetil G, et al. Successful autologous cord blood transplantation in a child with acquired severe aplastic anemia. Pediatr Transplant. 2013; 17:E104-107. [PubMed: 23464883] 
51. Im HJ, Koh KN, Choi ES, et al. Excellent outcome of haploidentical hematopoietic stem cell transplantation in children and adolescents with acquired severe aplastic anemia. Biol Blood Marrow Transplant. 2013; 19:754-759. [PubMed: 23380343]

52. Wang H, Yan H, Wang Z, et al. Cotransplantation of allogeneic mesenchymal and hematopoietic stem cells in children with aplastic anemia. Pediatrics. 2012; 129:e1612-1615. [PubMed: 22566416]

53. Eapen M, Horowitz MM. Alternative donor transplantation for aplastic anemia. Hematology Am Soc Hematol Educ Program. 2010; 2010:43-46. [PubMed: 21239769]

54. Bunin N, Aplenc R, Iannone R, et al. Unrelated donor bone marrow transplantation for children with severe aplastic anemia: minimal GVHD and durable engraftment with partial T cell depletion. Bone Marrow Transplant. 2005; 35:369-373. [PubMed: 15640818]

55. Bacigalupo A, Locatelli F, Lanino E, et al. Fludarabine, cyclophosphamide and anti-thymocyte globulin for alternative donor transplants in acquired severe aplastic anemia: a report from the EBMTSAA Working Party. Bone Marrow Transplant. 2005; 36:947-950. [PubMed: 16205733]

56. Frickhofen N, Heimpel H, Kaltwasser JP, et al. Antithymocyte globulin with or without cyclosporin A: 11-year follow-up of a randomized trial comparing treatments of aplastic anemia. Blood. 2003; 101:1236-1242. [PubMed: 12393680]

57. Samarasinghe S, Webb DK. How I manage aplastic anaemia in children. Br J Haematol. 2012; 157:26-40. [PubMed: 22348483]

58. Saracco P, Quarello P, Iori AP, et al. Cyclosporin A response and dependence in children with acquired aplastic anaemia: a multicentre retrospective study with long-term observation follow-up. Br J Haematol. 2008; 140:197-205. [PubMed: 18173756]

59. Dufour C, Svahn J, Bacigalupo A. Front-line immunosuppressive treatment of acquired aplastic anemia. Bone Marrow Transplant. 2013; 48:174-177. [PubMed: 23165493]

60. Fuhrer M, Rampf U, Baumann I, et al. Immunosuppressive therapy for aplastic anemia in children: a more severe disease predicts better survival. Blood. 2005; 106:2102-2104. [PubMed: 15933058]

61. Tichelli A, Schrezenmeier H, Socie G, et al. A randomized controlled study in patients with newly diagnosed severe aplastic anemia receiving antithymocyte globulin (ATG), cyclosporine, with or without G-CSF: a study of the SAA Working Party of the European Group for Blood and Marrow Transplantation. Blood. 2011; 117:4434-4441. [PubMed: 21233311]

62. Alsultan A, Goldenberg NA, Kaiser N, et al. Tacrolimus as an alternative to cyclosporine in the maintenance phase of immunosuppressive therapy for severe aplastic anemia in children. Pediatr Blood Cancer. 2009; 52:626-630. [PubMed: 19148946]

63. Kamio T, Ito E, Ohara A, et al. Relapse of aplastic anemia in children after immunosuppressive therapy: a report from the Japan Childhood Aplastic Anemia Study Group. Haematologica. 2011; 96:814-819. [PubMed: 21422115]

64. Brodsky RA, Chen AR, Dorr D, et al. High-dose cyclophosphamide for severe aplastic anemia: long-term follow-up. Blood. 2010; 115:2136-2141. [PubMed: 20018919]

65. Olnes MJ, Scheinberg P, Calvo KR, et al. Eltrombopag and improved hematopoiesis in refractory aplastic anemia. N Engl J Med. 2012; 367:11-19. [PubMed: 22762314]

66. Nishio N, Yagasaki H, Takahashi Y, et al. Natural history of transfusion-independent non-severe aplastic anemia in children. International journal of hematology. 2009; 89:409-413. [PubMed: 19343478]

67. Howard SC, Naidu PE, Hu XJ, et al. Natural history of moderate aplastic anemia in children. Pediatr Blood Cancer. 2004; 43:545-551. [PubMed: 15382271]

68. Brock K, Goldenberg N, Graham DK, et al. Moderate aplastic anemia in children: preliminary outcomes for treatment versus observation from a single-institutional experience. J Pediatr Hematol Oncol. 2013; 35:148-152. [PubMed: 23128338]

69. Marsh J, Schrezenmeier H, Marin P, et al. Prospective randomized multicenter study comparing cyclosporin alone versus the combination of antithymocyte globulin and cyclosporin for treatment of patients with nonsevere aplastic anemia: a report from the European Blood and Marrow Transplant (EBMT) Severe Aplastic Anaemia Working Party. Blood. 1999; 93:2191-2195. [PubMed: 10090926] 
70. Nimer SD, Ireland P, Meshkinpour A, et al. An increased HLA DR2 frequency is seen in aplastic anemia patients. Blood. 1994; 84:923-927. [PubMed: 8043874]

71. Sugimori C, Yamazaki H, Feng X, et al. Roles of DRB $1 * 1501$ and DRB $1 * 1502$ in the pathogenesis of aplastic anemia. Exp Hematol. 2007; 35:13-20. [PubMed: 17198869]

72. Fuhrer M, Durner J, Brunnler G, et al. HLA association is different in children and adults with severe acquired aplastic anemia. Pediatr Blood Cancer. 2007; 48:186-191. [PubMed: 16496287]

73. Yoshida N, Yagasaki H, Takahashi Y, et al. Clinical impact of HLA-DR15, a minor population of paroxysmal nocturnal haemoglobinuria-type cells, and an aplastic anaemia-associated autoantibody in children with acquired aplastic anaemia. Br J Haematol. 2008; 142:427-435. [PubMed: 18537977]

74. Scheinberg P, Wu CO, Nunez O, et al. Long-term outcome of pediatric patients with severe aplastic anemia treated with antithymocyte globulin and cyclosporine. J Pediatr. 2008; 153:814819. [PubMed: 18672253]

75. Kosaka Y, Yagasaki H, Sano K, et al. Prospective multicenter trial comparing repeated immunosuppressive therapy with stem-cell transplantation from an alternative donor as secondline treatment for children with severe and very severe aplastic anemia. Blood. 2008; 111:10541059. [PubMed: 17989314]

76. Scheinberg P, Nunez O, Young NS. Retreatment with rabbit anti-thymocyte globulin and ciclosporin for patients with relapsed or refractory severe aplastic anaemia. Br J Haematol. 2006; 133:622-627. [PubMed: 16704436]

77. Gupta V, Brooker C, Tooze JA, et al. Clinical relevance of cytogenetic abnormalities at diagnosis of acquired aplastic anaemia in adults. Br J Haematol. 2006; 134:95-99. [PubMed: 16803574]

78. Afable MG 2nd, Wlodarski M, Makishima H, et al. SNP array-based karyotyping: differences and similarities between aplastic anemia and hypocellular myelodysplastic syndromes. Blood. 2011; 117:6876-6884. [PubMed: 21527527]

79. Socie G, Mary JY, Schrezenmeier H, et al. Granulocyte-stimulating factor and severe aplastic anemia: a survey by the European Group for Blood and Marrow Transplantation (EBMT). Blood. 2007; 109:2794-2796. [PubMed: 17110459]

80. Niemeyer CM, Baumann I. Myelodysplastic syndrome in children and adolescents. Seminars in hematology. 2008; 45:60-70. [PubMed: 18179970]

81. Stalder MP, Rovo A, Halter J, et al. Aplastic anemia and concomitant autoimmune diseases. Ann Hematol. 2009; 88:659-665. [PubMed: 19139895]

82. Socie G, Henry-Amar M, Bacigalupo A, et al. Malignant tumors occurring after treatment of aplastic anemia. European Bone Marrow Transplantation-Severe Aplastic Anaemia Working Party. N Engl J Med. 1993; 329:1152-1157. [PubMed: 8377778]

83. Chapuis B, Von Fliedner VE, Jeannet M, et al. Increased frequency of DR2 in patients with aplastic anaemia and increased DR sharing in their parents. Br J Haematol. 1986; 63:51-57. [PubMed: 3458502]

84. Babushok DV, Li Y, Roth JJ, et al. Common Polymorphic Deletion of Glutathione S-Transferase Theta Predisposes to Acquired Aplastic Anemia: Independent Cohort and Meta-Analysis of 609 Patients. Am J Hematol. 2013 in press.

85. Young NS, Calado RT, Scheinberg P. Current concepts in the pathophysiology and treatment of aplastic anemia. Blood. 2006; 108:2509-2519. [PubMed: 16778145]

86. Shin SH, Lee JW. The optimal immunosuppressive therapy for aplastic anemia. Int J Hematol. 2013; 97:564-572. [PubMed: 23605367] 


\section{KEY POINTS}

- Acquired Aplastic Anemia (AA) is an acquired bone marrow failure condition characterized by peripheral pancytopenia and a hypoplastic bone marrow.

- There is increasing evidence that acquired AA is immune-mediated.

- Bone marrow transplantation (BMT) is the recommended first-line therapy for patients with an HLA-matched sibling donor, with 5-year survival rates exceeding $90 \%$.

- Immunosuppressive therapy (IST) with horse antithymocyte globulin and cyclosporine is the recommended first-line therapy for patients without an HLAmatched sibling donor. Survival rates are similar to BMT with a matched sibling donor, but relapse, clonal hematopoiesis, leukemia, autoimmunity, and cancer remain concerns that require long-term follow-up.

- BMT with an HLA-matched unrelated donor should be offered to all IST nonresponders early in the course of disease and may be considered as a first-line treatment in selected cases and in countries where horse antithymocyte globulin is not available.

- A better understanding of underlying mechanisms that initiate and fuel the immune dysregulation will help to develop targeted preventive strategies and more personalized and specific treatment options for patients with AA. 


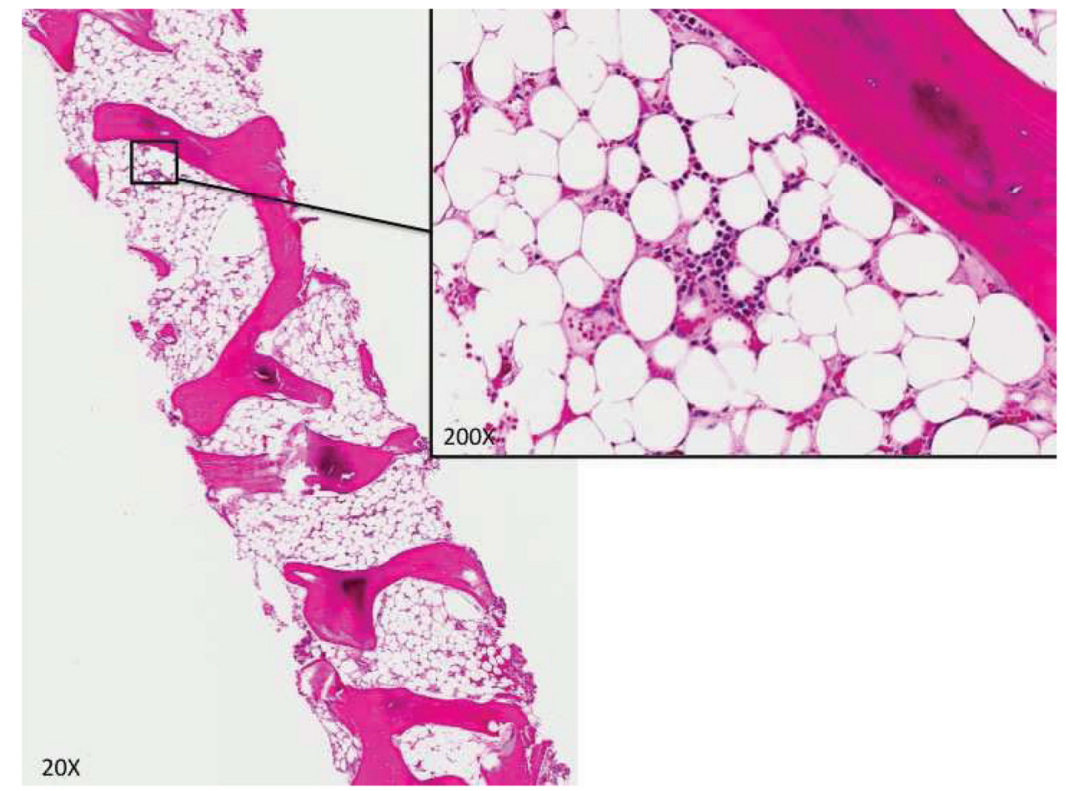

Figure 1.

Bone marrow aspirate and biopsy from a patient with acquired AA. Hematopoietic elements are greatly reduced, and there is replacement of marrow space with adipose tissue. Focal islands of left-shifted erythropoiesis (Fig 1: H\&E stain, original magnification $\times 20$; Inset: H\&E stain, original magnification $\times 200)$.

(Courtesy of Dr Michele E. Paessler, DO, Pathology, The Children's Hospital of Philadelphia.) 


\section{IBMFS}

\section{Acquired AA}

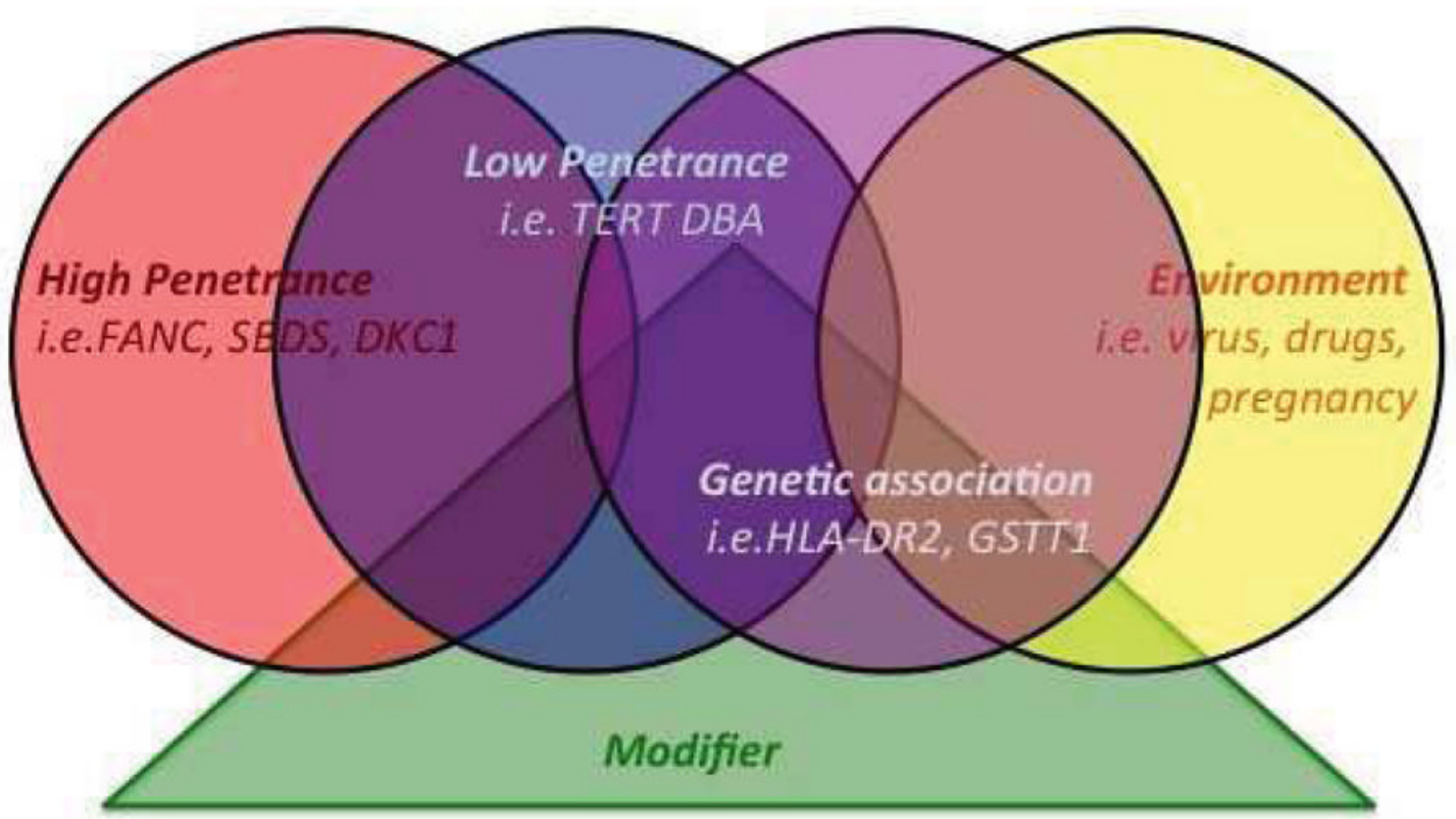

Figure 2.

Schematic representation of a relationship between genetic mutations, disease penetrance, and gene-environment interaction in the pathogenesis of bone marrow failure. Mutations with a high disease penetrance almost always cause disease, i.e. mutations in the Fanconi Anemia genes $(F A N C)$, in the SBDS gene causing Shwachman Diamond Syndrome, or in $D K C 1$ causing $\mathrm{X}$-linked Dyskeratosis Congenita. In contrast, mutations in genes with low disease penetrance may not manifest as clinically apparent bone marrow failure, examples include mutations in the TERT gene responsible for autosomal dominant Dyskeratosis Congenita or in certain DBA genes responsible for Diamond Blackfan Anemia. ${ }^{3}$ Genetic polymorphisms associated with AA don't cause disease in the majority of carriers but, in combination with other modifier genes and the appropriate environmental insult, may contribute to the development of AA. Examples are HLA-DR2 in adult AA and HLA-B14 in pediatric AA or GSTT1 gene deletions. ${ }^{70,72,83,84}$ 


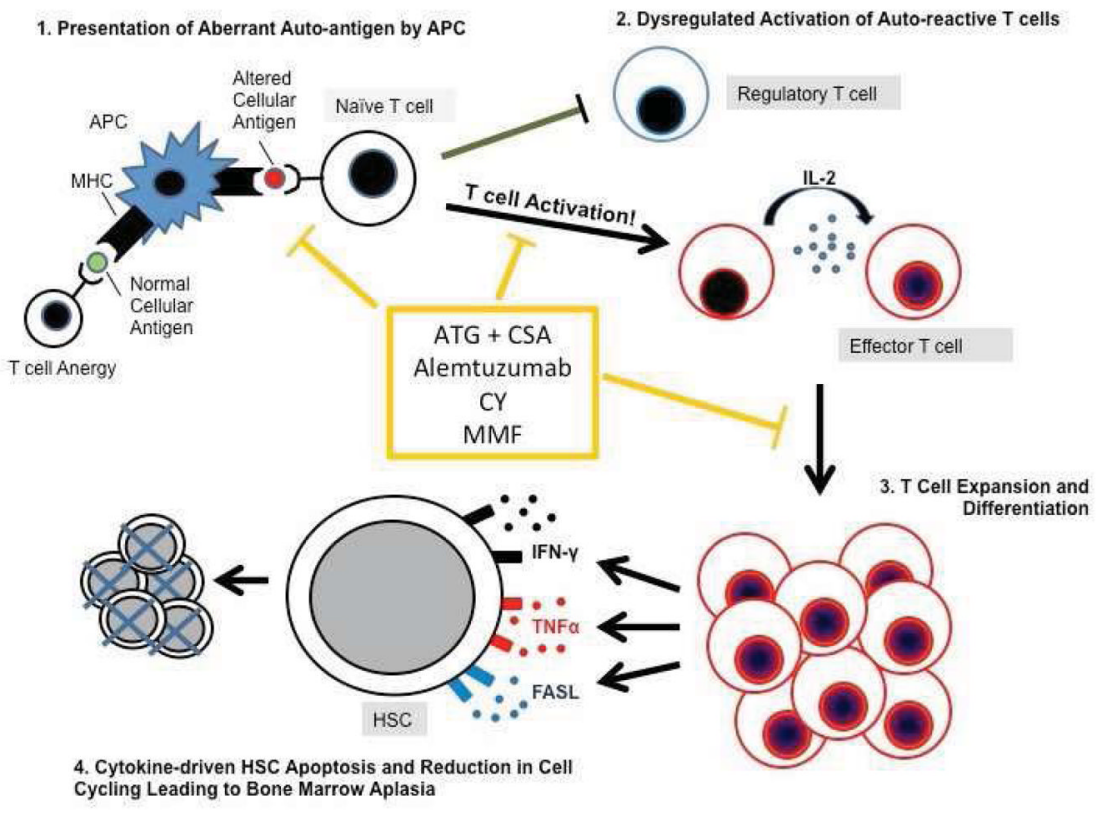

Figure 3.

Current evidence suggests that acquired AA results from the aberrant activation of one or more auto-reactive $\mathrm{T}$ cell clones due to alteration of antigens presented by the Major Histocompatibility Complex (MHC) on the surface of Antigen Presenting Cells (APC). This antigen alteration is triggered by viral infection, chemical exposure, or genetic mutation, and leads to the inappropriate activation of antigen-specific effector $\mathrm{T}$ cells and decreased activity of regulatory $\mathrm{T}$ cells, which normally serve to prevent auto-immunity. $\mathrm{T}$ cell activation leads to IL-2-driven expansion and differentiation of T cells into effector and memory $\mathrm{T}$ cells. These pro-inflammatory $\mathrm{T}$ cells produce a variety of cytokines, including FAS Ligand (FASL), interferon- $\gamma$ (IFN- $\gamma$ ), and Tumor Necrosis Factor a (TNFa), which 1) induce HSC apoptosis and 2) alter gene regulation and decrease protein synthesis to prevent HSC cell cycling, ultimately leading to bone marrow failure. Immune suppression therapy disrupts $\mathrm{T}$ cell-driven HSC destruction by inhibiting $\mathrm{T}$ cell responses at several points along this pathway. ${ }^{85,86}$ 


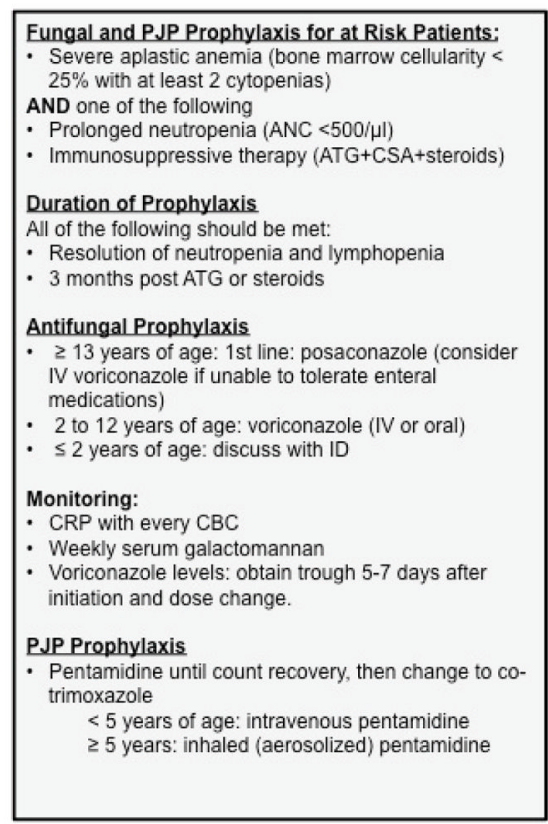

Eungal and PJP Prophylaxis for at Risk Patients: -

- Prolonged neutropenia (ANC $<500 / \mu$ )

CSA+steroids)

- Resolution of neutropenia and lymphopenia

- 3 months post ATG or steroids

Atifungal Prophylaxis

$\geq 13$ years of age: 1 st line: posaconazole (consider medications)

2 to 12 years of age. voriconazole (IV or ora)

Monitoring:

CRP with every CBC

Voriconazole levels: obtain trough 5-7 days after

tiation and dose change.

P Prophylaxis

Pentine until count recovery, then change to co-

5 years of age: intravenous pentamidine

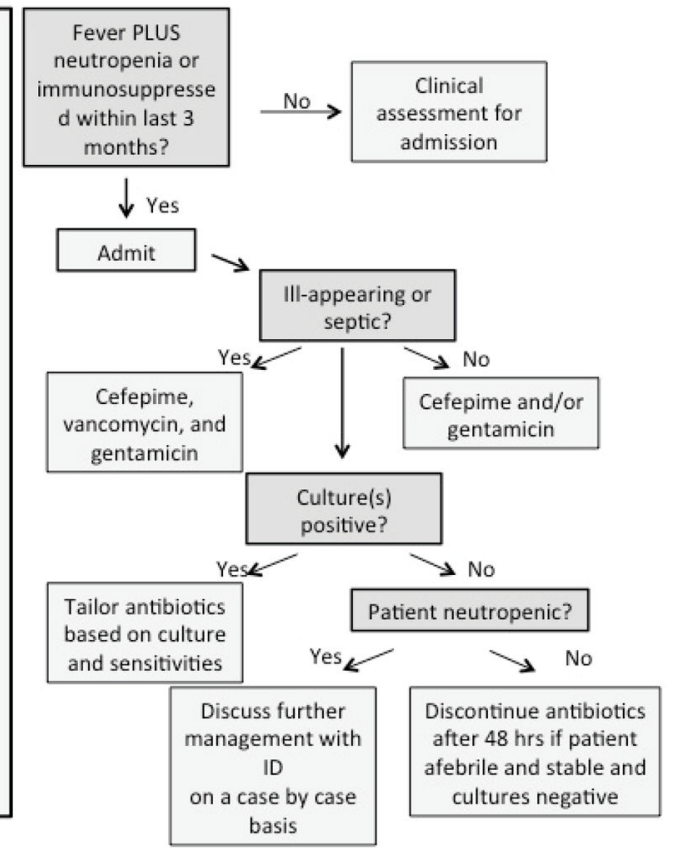

Figure 4.

Flow diagram for antimicrobial prophylaxis and empiric fever management for patients with severe aplastic anemia currently used at the Comprehensive Bone Marrow Failure Center CHOP/UPENN. PJP, Pneumocystis jiroveci pneumonia. (Courtesy of Drs. Talene Metjian PharmD, Brian T. Fisher, DO MSCE, Infectious Diseases, and Shefali Parikh, MD, Hematology, The Children's Hospital of Philadelphia) 


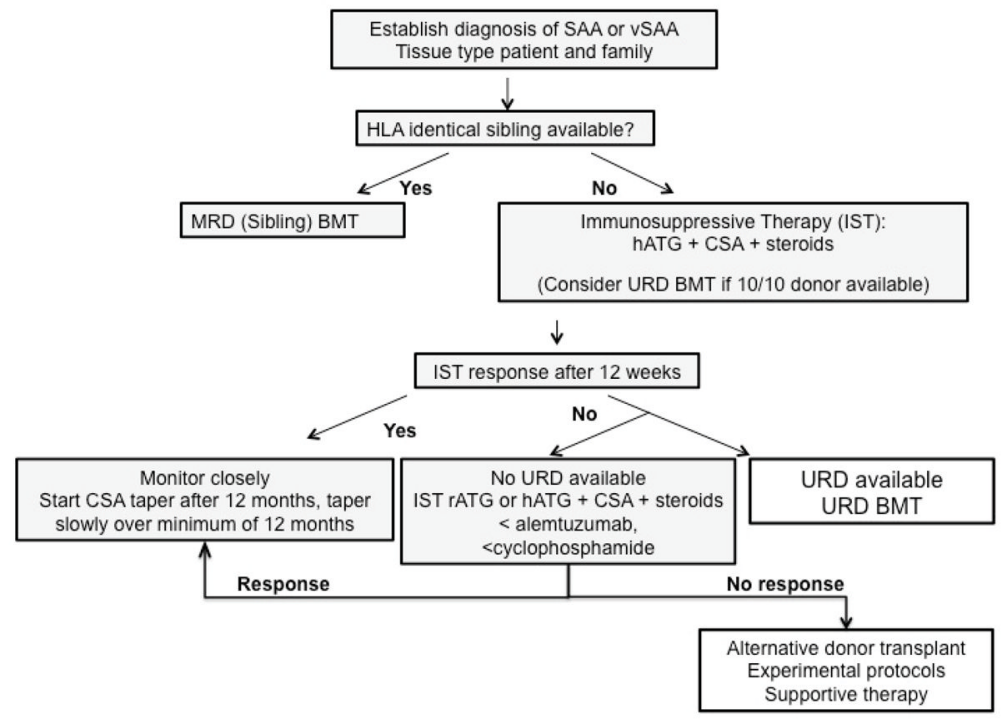

Figure 5.

Treatment algorithm for AA and sAA. MRD, matched related donor; hATG, horse antithymocyte globulin; rATG, rabbit antithymocyte globulin, CSA cyclosporine, URD unrelated donor; BMT bone marrow transplant; IST, immune suppressive therapy. 
Table 1

Etiologies Associated with Acquired AA

\begin{tabular}{|c|c|}
\hline Infectious & $\begin{array}{ll}\text { - } & \text { Hepatitis-associated, typically seronegative } \\
\text { - } & \text { Epstein-Barr Virus } \\
\text { - } & \text { Cytomegalovirus } \\
\text { - } & \text { Parvovirus } \\
\text { - } & \text { Mycobacterial Infections } \\
\text { - } & \text { Human Immunodeficiency Virus } \\
\text { - } & \text { Human Herpes Virus } 6 \\
\text { - } & \text { Varicella Zoster Virus } \\
\text { - } & \text { Measles } \\
\text { - } & \text { Adenovirus } \\
\text { - } & \text { and others }\end{array}$ \\
\hline Nutritional & $\begin{array}{ll}\text { - } & \text { Copper deficiency } \\
\text { - } & \text { Vitamin B12 } \\
\text { - } & \text { Folic acid }\end{array}$ \\
\hline \multicolumn{2}{|l|}{ Drugs } \\
\hline $\begin{array}{l}\text { Toxic } \\
\text { Idiosyncratic }\end{array}$ & $\begin{array}{ll}\text { - } & \text { Non-steroidal anti-inflammatory drugs } \\
\text { - } & \text { Antibiotics } \\
\text { - } & \text { Anticonvulsants } \\
\text { - } & \text { Sulfonamides } \\
\text { - } & \text { Gold Salts } \\
\text { - } & \text { Many additional agents rarely associated with aplastic anemia } \\
\text { - } & \text { Chloramphenicol }\end{array}$ \\
\hline Chemicals & $\begin{array}{ll}\text { - } & \text { Benzene } \\
\text { - } & \text { Insecticides } \\
\text { - } & \text { Pesticides } \\
\text { - } & \text { Solvents }\end{array}$ \\
\hline \multicolumn{2}{|l|}{ Radiation } \\
\hline Other Associations & $\begin{array}{ll}\text { - } & \text { Pregnancy } \\
\text { - } & \text { Inflammatory and autoimmune (e.g. systemic lupus erythematosus) } \\
\text { - } & \text { Graft-versus-Host-Disease }\end{array}$ \\
\hline Idiopathic & - Of unknown etiology, this term is increasingly replaced by "Immune-mediated AA" \\
\hline
\end{tabular}


Table 2

Features Suggestive of IBMFS in a Patient with Pancytopenia

\begin{tabular}{|c|c|}
\hline Clinical History & $\begin{array}{ll}\text { - } & \text { Failure to thrive } \\
\text { - } & \text { History of cytopenia, easy bruising and frequent infections } \\
\text { - } & \text { Malabsorption/maldigestion } \\
\text { - } & \text { Developmental Delay }\end{array}$ \\
\hline Family History & $\begin{array}{l}\text { - } \\
\text { - } \\
\text { - } \\
\text { - } \\
\text { - }\end{array}$ \\
\hline Physical Examination & $\begin{array}{ll}\text { - } & \text { Short Stature, congenital anomalies and dysmorphologies } \\
\text { - } & \text { Abnormal skin pigmentation, birth marks } \\
\text { - } & \text { Nail abnormalities } \\
\text { - } & \text { Limb (especially forearm) abnormalities } \\
\text { - } & \text { Other skeletal abnormalities } \\
\text { - } & \text { Renal and GU abnormalities } \\
\text { - } & \text { Cardiac abnormalities } \\
\text { - } & \text { Eye abnormalities } \\
\text { - } & \text { Cleft lip/palate } \\
\text { - } & \text { Hair or teeth abnormalities } \\
\text { - } & \text { Developmental delay }\end{array}$ \\
\hline Laboratory Work-up & 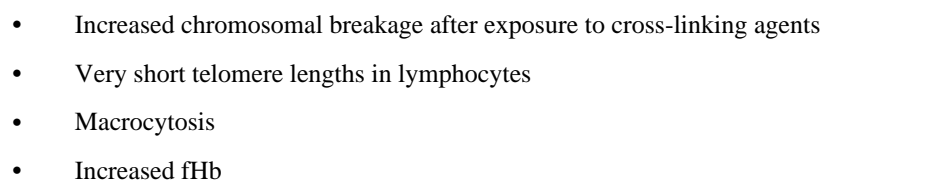 \\
\hline
\end{tabular}

$\mathrm{fHb}$, fetal hemoglobin 
Table 3

Clinical Evaluation of Aplastic Anemia

\begin{tabular}{|c|c|}
\hline $\begin{array}{l}\text { 1. Establishing Diagnosis } \\
\text { and Severity of AA }\end{array}$ & $\begin{array}{ll}\text { - } & \text { Clinical history and physical examination } \\
\text { - } & \text { Complete blood count and differential } \\
\text { - } & \text { Reticulocyte count } \\
\text { - } & \text { Peripheral blood smear } \\
\text { - } & \text { Bone marrow aspirate and biopsy } \\
\text { - } & \text { Bone marrow cytogenetics } \\
\text { - } & \text { Liver function tests, serum bilirubin, LDH }\end{array}$ \\
\hline $\begin{array}{l}\text { 2. Exclusion of Inherited } \\
\text { Bone Marrow Failure } \\
\text { Syndromes (IBMFs) }\end{array}$ & $\begin{array}{ll}\text { - } & \text { Clinical history } \\
\text { - } & \text { Family history } \\
\text { - } & \text { Physical examination } \\
\text { - } & \text { Chromosomal breakage studies in peripheral blood } \\
\text { - } & \text { Telomere length measurement in peripheral blood } \\
\text { - } & \text { Increased fHb (several IBMFs) } \\
\text { - } & \text { Consider } c-m p l \text { testing } \\
\text { - } & \text { Consider additional diagnostic and genetic testing for IBMFS if suspected }\end{array}$ \\
\hline $\begin{array}{l}\text { 3. Assess for Specific } \\
\text { Etiologies and } \\
\text { Association }\end{array}$ & $\begin{array}{ll}\text { - } & \text { Viral Serology (hepatitis virus panel, CMV, EBV, parvovirus, VZV, HSV, HHV6, HIV, adenovirus) } \\
\text { - } & \text { Flow cytometry of peripheral blood for Paroxysmal Nocturnal Hemoglobinuria (PNH) } \\
\text { - } & \text { Vitamin B12 and Folate } \\
\text { - } & \text { Copper, Ceruloplasmin, Zinc } \\
\text { - } & \text { Immunology: lymphocyte subsets (including CD4+, CD25+ regulatory T cells), quantitative } \\
\text { immunoglobulins } \\
\text { - } & \text { Autoimmune or inflammatory disease evaluation } \\
\text { - } & \text { HLA typing } \\
\text { - } & \text { Pregnancy test } \\
\text { - } & \text { T cell receptor rearrangement }\end{array}$ \\
\hline
\end{tabular}

In bold; test routinely performed in all patients investigated for AA 
Table 4

Basic Principles of Neutropenic Precaution for Pediatric AA patients

\begin{tabular}{|lll|}
\hline AVOID & RECOMMEND & CONSIDER \\
\hline Construction areas & Frequent hand washing & Air quality control \\
Garbage, compost, potted plants & Hospital guidelines for hygienic routine & Barrier isolation \\
Unpasteurized dairy products and fruit juices & Prophylactic antifungals & Prophylactic antibiotics \\
Uncooked meats, seafood, eggs & & \\
Unwashed fruits and vegetables & G-CSF with IST & \\
Raw nuts and dried fruits & & \\
Crowded rooms with no air quality control & & \\
Vaccinations with live vaccines & & \\
Tampon use for women & & \\
Situation where may get injured, i.e & & \\
Manicures or pedicures, & & \\
\hline
\end{tabular}

Pneumocystis jirovecii pneumonia, PJP 
Table 5

Current Approaches to BMT for Pediatric Acquired AA Patients

\begin{tabular}{|ll}
\hline Conditioning & \\
Matched Related Donor & ATG + Cyclophosphamide \\
Matched Unrelated Donor & ATG + Fludarabine + Cyclophosphamide ${ }^{a}+/ \mathrm{TBI}^{b}$ \\
Mismatched Unrelated, Haploidentical, or & Clinical Trials Ongoing \\
Cord Blood & \\
GVHD/Rejection Prophylaxis & CSA/Tacrolimus +/- MTX/MMF \\
Agents & $\searrow 6$ months followed by slow taper \\
Duration of CSA/Tacrolimus & \\
Antimicrobial Prophylaxis & TMP/SMX (First-line) or alternative x 1 year \\
Pneumocystis Jiroveci & Acyclovir x 1 year if past history of infection or positive HSV serology \\
HSV/VZV & Prophylaxis based on donor/recipient serology \\
CMV & Prophylaxis prior to neutrophil engraftment or during immune suppression treatment for \\
Antifungal & GVHD \\
Antibacterial & Penicillin if asplenic or for prolonged Chronic GVHD
\end{tabular}

$a_{\text {Optimal dose unknown, subject of ongoing clinical trials. }}$

${ }^{b}$ Included in the United States, omitted in European regimens for younger pediatric patients. ATG, anti-thymocyte globulin; TBI, total body irradiation; CSA, cyclosporin; MMF, mycophenolate mofetil; TMP/SMX, trimethoprim-sulfamethoxasole 
Table 6

Late Effects of BMT for Pediatric Acquired AA Patients

\begin{tabular}{|c|c|c|}
\hline \multirow[b]{3}{*}{ Endocrine } & \multicolumn{2}{|r|}{ Conditioning Regimen } \\
\hline & Chemotherapy Alone & HD TBI + Chemotherapy \\
\hline & & \\
\hline Growth abnormalities & Rare & Uncommon \\
\hline Infertility & Rare in females, may occur in males & Common \\
\hline Impaired Pubertal Development & Rare in females, may occur in males & Common \\
\hline Thyroid dysfunction & Rare & Common \\
\hline Second Malignancy & Uncommon: Skin/oral cancer ${ }^{a}$ & Common: Skin/oral ${ }^{a}$, meningiomas, breast, thyroid, head/neck \\
\hline Vision & $\operatorname{Rare}^{a}$ & Cataracts \\
\hline Cardiovascular & Hypertension ${ }^{a}$ & Hypertension $^{a}$, Metabolic Syndrome \\
\hline Pulmonary, hepatic, GI & Uncommon $^{a}$ & Restrictive Lung Disease \\
\hline Renal & Uncommon $^{b}$ & Uncommon $^{b}$ \\
\hline \multicolumn{3}{|l|}{ Bone } \\
\hline Avascular Necrosis & Uncommon $^{a}$ & Uncommon $^{a}$ \\
\hline Decreased Bone Density & Common $^{a}$ & Common $^{a}$ \\
\hline Dental & Common $^{c}$ & Common $^{c}$ \\
\hline Neurocognitive & Uncommon $d$ & Uncommon $d$ \\
\hline
\end{tabular}

${ }^{a}$ Strongly associated with Chronic GVHD and long-term steroid treatment.

${ }^{b}$ Usually associated with calcineurin inhibitors or nephrotoxic antimicrobials.

${ }^{c}$ Increased risk of abnormal development of permanent teeth, retention of primary teeth, poor mineralization, and caries: requires regular dental screening (every 6 months).

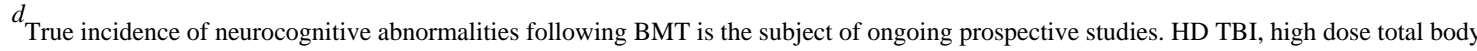
irradiation. 
Table 7

Immunosuppressive Therapy for Severe Aplastic Anemia

\begin{tabular}{|c|c|c|c|}
\hline DRUG & DOSE & ROUTE & Schedule \\
\hline $\begin{array}{c}\text { ATGAM (Equine } \\
\text { Antithymocyte Globulin, } \\
\text { hATG) }\end{array}$ & $40 \mathrm{mg} / \mathrm{kg} / \mathrm{day}$ & IV & $\begin{array}{c}\text { Day } 1-4 \\
\text { Initial dose over } 8-10 \text { hours, subsequent doses over } 6-8 \text { hours }\end{array}$ \\
\hline Cyclosporine $^{2}$ (CSA) & $\begin{array}{l}5-15 \mathrm{mg} / \mathrm{kg} / \text { day divided in } 2 \\
\text { doses }\end{array}$ & $\mathrm{PO}$ & $\begin{array}{l}\text { Starting on day } 1(\text { or } 5) \\
\text { Target trough blood level } 200-400 \mathrm{ng} / \mathrm{ml} \text {. } \\
\text { For } 12 \text { months after stable CR or PR } \\
\text { Then taper over } 12 \text { months }\end{array}$ \\
\hline Methyl- prednisolone ${ }^{3}$ & 1 or $2 \mathrm{mg} / \mathrm{kg} /$ day & $\mathrm{IV} / \mathrm{PO}$ & $\begin{array}{l}\text { Day } 1-5 \text {, before ATG infusion } \\
\text { Change to } 1 \mathrm{mg} / \mathrm{kg} / \text { day prednisone po day } 6-10 \text {, then } \\
\text { individualize taper over } 14 \text { days }\end{array}$ \\
\hline G-CSF & Starting dose $3-5 \mu \mathrm{g} / \mathrm{kg}$ daily & SQ & $\begin{array}{l}\text { If ANC }<500 / \mu 1 \\
\text { Wean if consistently ANC }>500 / \mu 1\end{array}$ \\
\hline
\end{tabular}

${ }^{1}$ Antihistamine and oral antipyretics are given before each ATG infusion (i.e. acetaminophen and dyphenhydramine)

2 Reduce cyclosporine dose to one half when given concomitantly with voriconazole.

${ }^{3}$ H2-receptor antagonists (ranitidine) or a proton pump inhibitor (latter might worsen CSA associated hypomagnesemia) should be considered for peptic ulcer prophylaxis with high dose steroids. 


\section{Table 8}

Long-Term Follow-up after IST

\begin{tabular}{ll} 
- & CBC, reticulocyte counts, CRP, initially at least weekly \\
- & CSA level, creatinine, liver enzymes, serum bilirubin, magnesium monitoring \\
- Transfusion support if hemoglobin $<8 \mathrm{~g} / \mathrm{dl}$, platelets $<10,000 / \mathrm{mcl}$ \\
- Close monitoring for infections \\
\hline - $\quad$ Repeat bone marrow aspirate, biopsy and cytogenetics at 3 months and 12 months or at sustained worsening of cytopenias \\
\hline - PNH testing annually \\
- Auto-immune disease screening at regular intervals (every $2-3$ years) \\
\hline Transition to a specialty care center in the adult health care system which is familiar with the treatment and follow-up of patients \\
with AA
\end{tabular}

Pediatr Clin North Am. Author manuscript; available in PMC 2014 December 01. 